\title{
Anti-CTLA4 MoAb RNA-transfected Autologous Dendritic Cell Vaccine
}

National Cancer Institute

\section{Source}

National Cancer Institute. Anti-CT LA4 MOAb RNA-transfected Autologous Dendritic Cell

Vaccine. NCI Thesaurus. Code C94217.

An autologous dendritic cell (DC) cancer vaccine with potential immunostimulatory activity. Anti-CT LA4 MoAb RNA-transfected autologous DC vaccine is prepared by transfecting DCs with RNAs encoding humanized heavy and light chains of the antiCT LA4 (cytotoxic T-Lymphocyte-Associated Antigen 4); expression of anti-CT LA4 blocks the inhibitory effect of CT LA4 on the activation of T-lymphocytes. Co-vaccination of this vaccine with melanoma antigen specific vaccine may eliminate the adverse effects associated with systemic administration of immune modulators, while also enhancing vaccine-induced immune responses. 